\title{
СОЦИАЛЬНЫЕ ИНВЕСТИЦИИ И ИХ ВЛИЯНИЕ НА ЭКОНОМИЧЕСКОЕ РАЗВИТИЕ ГОСУДАРСТВА
}

\section{(c) 2021 Павлюков Александр Викторович}

студент-магистр

Университет ИТМО, Россия, Санкт-Петербург

E-mail: off.mail.pavlyukov.a.v@gmail.com

\section{(C) 2021 Язев Ярослав Вячеславович}

студент-магистр

Университет ИТМО, Россия, Санкт-Петербург

E-mail: yaroslav.v.yazev@gmail.com

\section{(c) 2021 Пашинцева Виктория Сергеевна}

студент-магистр

Университет ИТМО, Россия, Санкт-Петербург

E-mail: victoria.polukhina@mail.ru

(c) 2021 Хэлльстром Анастасия Константиновна

студент-магистр

Университет ИТМО, Россия, Санкт-Петербург

E-mail: nastya_zem@mail.ru

(c) 2021 Хэлльстром Денис Александрович

студент-магистр

Университет ИТМО, Россия, Санкт-Петербург

E-mail: dion.hellstrom@yandex.ru

Научная статья посвящена проведению исследовательского анализа теоретической характеристики понятия «социальные инвестиции» и их практической роли при формировании экономического развития Российской Федерации. Актуальность исследования обусловлена тем, что социальные инвестиции способны создавать социально-ориентированные предприятия, деятельность которых удовлетворяет социальные потребности общества государства. В рамках статьи рассмотрены теоретические аспекты понятия «социальные инвестиции». Проанализировано их влияние на экономическое развитие России. Выделены актуальные проблемы и перспективы развития социальных инвестиций в российском государстве.

Ключевые слова: социиальные инвестиции, экономическое развитие, экономический рост, социиальная деятельность, социальные предприятия, социально-экономическое развитие.

Для каждой компании, функционирующей в любой сфере экономики, важно формирование такой модели управления, при которой в равной степени будут удовлетворены потребности и интересы всех заинтересованных лиц, как рабочего персонала, менеджмента, акционеров, так и общества с органами государственной власти. Одним из механизмов эффективного управления, позволяющего создавать фундамент для реализации стратегии устойчивого развития, выступает проведение социальных инвестиций.

Актуальность научного исследования на тематику «социальные инвестиции и их влияние на экономическое развитие государства» обусловлена тем, что социальные инвестиции способны создавать социально-ориентированные предприятия, деятельность которых удовлетворяет социальные потребности общества государства.

По этой причине, целью научной работы выступает проведение исследовательского анализа теоретической характеристики понятия «социальные инвестиции» и их практической роли при формировании экономического развития Российской Федерации.

Следует отметить, что категория социальных 
инвестиций исключительно широка и включает в себя корпоративную социальную ответственность, государственные инвестиции в социальную сферу, институциональные социальные инвестиции [6].

В трактовке Ассоциации менеджеров России социальные инвестиции бизнеса - это материальные, технологические, управленческие или иные ресурсы, а также финансовые средства компаний, направляемые по решению руководства на реализацию социальных программ, разработанных с учетом интересов основных внутренних и внешних заинтересованных сторон в предположении, что в стратегическом отношении компанией будет получен определенный социальный и экономический эффект [6].

Практическая роль социальных инвестиций в российском государстве заключается в двух важных вещах [1]:

1. Компании, занимающиеся социальным предпринимательством и вкладывающие свой финансовый капитал в социальные проекты, имеют более успешные позиции при конкурентной борьбе на рынках. На сегодняшний день социальная деятельность бизнеса - это положительный фактор, формирующий рост стоимости компании и повышение ее репутации/имиджа.

2. Социальные инвестиции способствуют повышению уровня и качества жизни населения, обеспеченности гражданской инфраструктурой, в конечном счете, степени развития человеческого капитала страны. Формируются основы для социального и экономического развития.
Наиболее популярной формой положительного влияния социальных инвестиций на экономическое развитие государства является формирование российскими предприятиями корпоративной-социальной ответственности.

В широком смысле корпоративная-социальная ответственность (КСО) представляет собой добровольный вклад бизнеса в развитие общества в социальной, экономической и экологической сферах, зачастую не связанный напрямую с основной деятельностью фирмы и выходящий за рамки определенного законодательного минимума и принятых в обществе этических норм [2].

На сегодняшний день политика корпоративной-социальной ответственности российских организаций строится на основе системы из трех уровней, изображенной на рисунке 1 .

На первом уровне корпоративной социальной ответственности происходит соблюдение стандартов и законодательства. Главный посыл - функционирование бизнеса и ведение коммерческого дела в легальном поле, поскольку актуальной для российского пространства проблемой выступает уход в теневой сектор экономики, а также уклонение от уплаты налогов при расчетах с бюджетом.

На втором уровне корпоративной социальной ответственности происходит формирование внутриорганизационных отношений предприятия со своим рабочим персоналом. Внутренний маркетинг персонала, система мотивации, вовлеченности и организация рабочих мест демон-

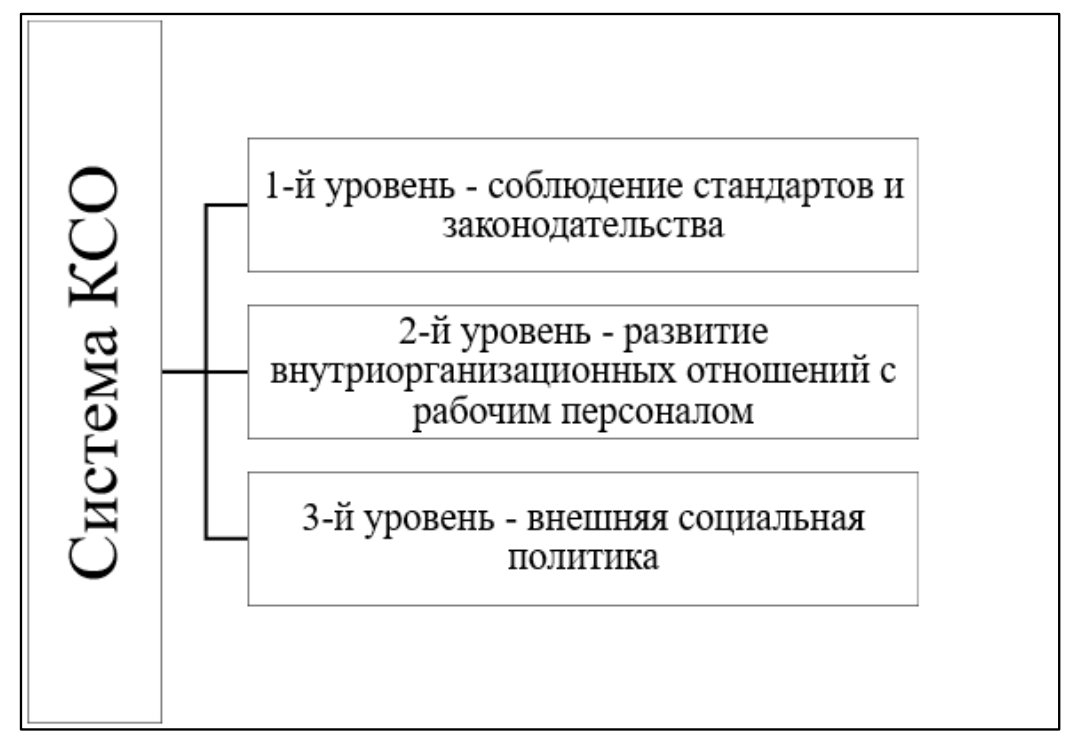

Puc. 1. Уровни системы КСО в управлении предприятий [составлено автором на основе источника 3]. 
стрируют заботу организации о своих сотрудниках.

На третьем уровне корпоративной социальной ответственности формируется внешняя социальная политика, в рамках которой и наблюдается основная доля мероприятий, направленных на управление КСО в российских компаниях. Ее потребителями выступают большее число заинтересованных лиц.

Исходя из уровней системы корпоративнойсоциальной ответственности в управлении, предприятия формируют те или иные методы/ модели управления своей социальной деятельности.

Практическая эффективность ориентация бизнес-модели на социальные инвестиции в российских компаниях позволяет повышать конкурентоспособность, имидж и стоимость бренда. На уровне государства - это формирует стимул развития социальные проектов и предприятий, создаются новые блага и объекты производства, которые удовлетворяют потребности общества.

По мнению авторов, современный этап развития социальных инвестиций в России сталкивается с рядом следующих проблем, среди которых $[4 ; 5]$ :

1. Применение концепции корпоративнойсоциальной ответственности, в рамках которой проводятся социальные инвестиции, противоречит главному смыслу ведения бизнеса - максимизации финансового результата (прибыли), поскольку реальный экономический эффект от реализации проектов КСО рассчитать затруднительно, а ресурсы для их проведения необходимы иногда колоссальные.

2. На уровне предприятия отсутствует принятие внутренних кодексов этики и развития этической политики, из-за чего социальные проекты и политика корпоративной-социальной ответственности не принимается внутренними стейкхолдерами предприятия.

3. Российская практика ведения бизнеса характеризуется низким уровнем подотчетности и транспарентности. В свою очередь, отсутствует сама модель эффективного корпоративного управления. В связи с этим, социальные инвестиции не могут принести эффективность конечного результата, поскольку ее показатели не будут включены в систему отчетности организации.
Однако, несмотря на это, перспективы развития социальных инвестиций в российской экономике крайне высоки. В первую очередь, это обусловлено социально-экономической эффективностью для самих предприятий, финансовый капитал которых направлен на реализацию социальных проектов, ориентированных под политику КСО. Благодаря этому создаются новые рабочие места, качество производимой продукции повышается, а экологическая безопасность стремиться к максимальным значениям.

Крайне важными социальные инвестиции для экономического развития нашего государства являются и через призму «зеленой экономики». Основными социально-экономическими последствиями социальных инвестиций при переходе к «зеленой экономике» будут выступать [7]:

1. Повышение эффективности управления энергетическими затратами на производственных объектах.

2. Повышение уровня экологической и технологической безопасности на объектах производства в промышленном секторе экономики.

3. Снижение выбросов СО2 в атмосферу и уровня загрязнения окружающей среды.

4. Обновление основных фондов и снижение размера себестоимости производства продукции.

Все эти аспекты позволяют формировать новый вектор будущего развития национальной экономики, поскольку производственные расходы предприятий снижаются, а эффективность и производительность труда - повышаются. Создаются условия, которые стимулируют внедрение зеленых технологий. Это позволяет формировать новую отрасль экономики Российской Федерации - наукоемкую промышленность с производством продукции высокой добавленной стоимости, что будет достаточно для создания новых триггеров экономического роста государства.

Таким образом, подводя итоги научной работы, можно заключить, что социальные инвестиции имеют положительное влияние на экономическое развитие государства, поскольку повышают стоимость социальноориентированного бизнеса, его конкурентоспособность и экономическую эффективность, а также формируют условия для роста уровня и качества жизни населения. 


\section{Библиографический список}

1. Панова А.Ю. Социальные инвестиции российского бизнеса: динамика и структура // Международный научно-исследовательский журнал. 2017. № 04 (58) Часть 3. С. 112-117.

2. Авилова М.Г. Корпоративная социальная ответственность в России: тенденции, проблемы, решения // Научно-методический электронный журнал «Концепт».-2016. - Т. 34.- С. 1-5.

3. Колесников Д.В., Строков М.А. Концепция социальной ответственности бизнеса: теоретический аспект // Вестник государственного и муниципального управления. 2017. № 1.- С. 99-105.

4. Басова М. М. Основные проблемы корпоративной социальной ответственности бизнеса и пути их решения // Стратегии бизнеса. 2017. № 2 .

5. Келарев В.В., Шаповаленко В.Г. Ключевые проблемы внедрения принципов корпоративной социальной ответственности в систему управления организацией. URL: http://www.e-rej.ru/upload/iblock/cf3/cf3cd1e823d 4f75541e8e0146f89247c.pdf (дата обращения: 28.08.2021).

6. Колесников Д.В. Социальные инвестиции как основная форма реализации социальной ответственности бизнеса // Научные Записки ОрелГИЭТ. 2019. № 3 (31). С. 4-8.

7. Халил M.P. Концепция зеленой экономики: основные положения и перспективы, экономические механизмы и условия перехода к зеленой экономике // Молодой ученый. 2018. № 45. С. 98-100. 